\title{
Editorial: teacher education for the 21st century
}

\author{
Woon-Chia Liu ${ }^{1}$ • Ee-Ling Low ${ }^{1}$
}

Published online: 16 September 2015

C) Springer Science+Business Media Dordrecht 2015

This special issue of the Educational Research in Policy and Practice (ERPP) features a collection of papers, which have been developed from the presentations and discussions from the World Education Research Association-International Research Network (WERAIRN) Teacher Education Symposium 2013 entitled Teacher Education for the 21st century: Developing teachers who are thoughtful, reflecting and inquiring. The goal of WERA-IRNs is to serve as a collaborative platform that can help advance research on educational issues internationally with a focus on specific topics.

Approaches to teacher education and preparation may vastly differ across different cultures and contexts. However, established teacher education programs have, as their focal point, learners who form the core of their educational endeavors. Such respected programs also emphasize the importance of enhancing the theory-practice nexus and on constantly developing a strong sense of teacher identity and teaching competencies.

The meteoric increase in technological advancement in the last few decades has dramatically transformed how people live their lives. Innovation is seen to be essential as it ensures sustainable growth in a knowledge-based economy and a competitive global marketplace. Education for the twenty-first century is about developing multiple intelligences and this demands for a holistic education system committed to enabling a learner to achieve his/her maximum potential. The learning environment in the twenty-first century needs to encompass a multiplicity of places, ideas, and people that is technologically driven and often, a virtual rather than a physical space. The responsibility for creating such an environment lies in the teacher. Tan in his paper "Innovating Teacher Education in a Complex Era" focuses on the role that teachers play in designing a powerful learning environment to drive twenty-first century learning and how teacher education must be re-designed to bring about possibilities of innovation.

$\bowtie$ Woon-Chia Liu

woonchia.liu@nie.edu.sg

Ee-Ling Low

eeling.low@nie.edu.sg

1 National Institute of Education, Nanyang Technological University, Singapore, Singapore 
In the next paper, Jensen, Skibsted, and Christensen researched on the development of relational competence in both theory and practice. Relational competence, the competence to establish and maintain good teacher-student relations, is a central and important one for a teacher in today's schools and is a decisive factor for learning outcomes. This conceptual paper explains the theoretical ideas, implications, and perspectives as well as the overall aims and the structure of the research project. The project's overall aim is to break new ground in pedagogical research and teacher education and the goal is to contribute to the development of theoretical knowledge within this academic field, so that relational competence can be understood and taught as part of ongoing development of teacher professional competence.

Rasmussen's study focused on developing better solutions to the problematic, weak, or even sometimes totally missing link between theory (teaching at college) and practice (teaching internship) in teacher education. The objective of the study was to investigate whether selected actions had the potential for bridging the gap between teaching at college and teaching practice, and to generate knowledge about difficulties and barriers that have to be overcome if these actions are to be implemented. Difficulties and barriers were found in the performance of the three different parties in the teacher education process (college teachers, practice teachers, and student teachers) and in the college teachers' approach to teaching in which the responsibilities of college teachers and student teachers were not clearly differentiated and described.

Following a major shift in Swiss teacher education in the 1990s, teachers are now educated at the university level with a more research-oriented focus than before the reform. Furthermore, the curriculum in teacher education is not only more academically oriented, but also concurrently practice-focused. This approach provides more learning opportunities that help to strengthen the relationship between theory and practice. Since the reform, reflection has been strongly embedded in the entire curriculum in order to support student teachers' reflective competence. Kamm discusses how students can be supported in developing a reflective attitude and a research-oriented stance, which have traditionally been seen as core elements of professional development. Three learning settings are presented, ranging from a more traditional approach to conducting research, to a current video-based training program. Finally, implications for teacher education are discussed.

Huang, in her paper "Cultivating teacher thinking: Ideas and practice" develops, through a literature analysis, a portrait of the functioning and practice of teacher thinking at the government and university levels. Teacher thinking is defined as habits and strategies or the habit of thinking used to collect information, analyze, understand institution, reflect, solve problems, inform decisions, initiate action, and accumulate practical wisdom. Teachers develop the habit of accumulating practical wisdom to make good decisions for student learning. Policy makers can help enact teacher professional standards and teacher education curricula to develop the requisite thinking skills desired. Field experience at the university level should also be designed to involve multiple teaching strategies and a coherent and consistent learning experience in different educational courses, which will help foster thinking habits that can help student teachers accumulate practical wisdom. Portfolio assessment, performance-based assessment, and teacher situational judgment tests can be used to assess teacher candidates' thinking and cognition regarding teaching and learning.

The paper by Tine Sloan "Data and learning that affords program improvement: A response to the U.S. accountability movement in teacher education" focuses on the teacher education program at the University and California, Santa Barbara (UCSB) in USA. The teacher education program at UCSB includes concurrent courses and fieldwork within an inquiry-based program to bridge the gap between theory and practice. The paper highlights the considerable reliance on licensure by the teacher education institutions to measure teacher quality. 
As several states in USA have implemented the licensing of teachers as professional by introducing a Professional Certificate of Effective Practices and the National Performance Assessment (edTPA) to improve the teacher quality. However, there is still a dearth of information within the field on how programs use such data to improve practice. Given the rather limited research on how programs use data to improve, the following research study offers a case analysis of faculty learning as a function of data use for program improvement. In this self-reported survey, both the rubrics scores and survey scores provided direction on where the program might focus improvement efforts but the tangible, authentic, integrated nature of the TPA data were essential for faculty to "see" what candidates were doing in their teaching practice. Further, the holistic nature of the assessment produced evidence that went beyond what faculty had access to in their individual practice, and it provided direct evidence of how their work with candidates was actually taken up in candidates' teaching and their K-12 students' learning. It was a strong motivator to improve individual and collective work. A central assumption of this view is that learning is best understood as a process embedded in social relationships and social practices. The analysis of learning thus focuses on changes in the ways individual's participates in social practices over time and across settings thus developing their competency as professionals.

There may be agreement internationally that the quality of teaching is a critical element of today's teacher education but there exists a wide range of views about how to develop thoughtful, reflective, inquiring, and thinking teachers to meet the challenges of today's and future educational needs. In the teacher education program highlighted in this issue, there is the clarity in the stance that teaching as a profession has strong mission for knowledge-based system of education that strives to offer equitable opportunity to all. To raise the quality of teachers, it is also important to elevate the status of teachers so as to make teaching as an attractive lifelong career of people who consider teaching as their calling and are motivated for lifelong learning. The teacher is not merely a teacher of a particular subject but a person who places the learner at the heart of his/her job and one who hold the heavy responsibility as a preserver and custodian of societal values. Thus, all the effort in meeting the challenges of changing scenarios confronting education should invariably start with raising standards in teacher recruitment, preparation, their accreditation, and enhancing the quality of ongoing professional development by infusing a strong inquiry focus, reflections on current practices, and ensuring a strong theory-practice nexus.

Collectively, as a special issue, common themes can be considered to have emerged from what the different teacher education programs are endeavoring to focus on in the quest to prepare teachers for the twenty-first century who are thoughtful, reflecting, and inquiring. Some of these include a strong university-based teacher education program interspersed with on-site clinical field experience in schools, many opportunities for reflection and for learning through practice and a strong inquiry-based stance. Ultimately, all these programs have the common goal of trying to develop thoughtful, reflecting, and inquiring teachers with the competencies required to meet the challenges of twenty-first century classrooms. 